\title{
Effect of Metallic Bipolar Plates Fillet Radii on Fuel Cell Performance
}

\author{
Chien-Ju Hung ${ }^{1}$, Wei-Jen Chen ${ }^{2}$, Chao-An Lin ${ }^{1} \oplus$, Huan-Ruei Shiu ${ }^{3}$ and Bin-Hao Chen ${ }^{4, *}$ \\ 1 Department of Power Mechanical Engineering, National Tsing Hua University, Hsinchu 30013, Taiwan; \\ cj.hung@gunitech.com (C.-J.H.); calin@pme.nthu.edu.tw (C.-A.L.) \\ 2 Department of Aeronautical Engineering, Chaoyang University of Technology, Taichung 413310, Taiwan; \\ t2018092@cyut.edu.tw \\ 3 GUNITECH CORP., Hsinchu 30741, Taiwan; ray.shiu@gunitech.com \\ 4 Department of Vehicle Engineering, National Taipei University of Technology, Taipei 106344, Taiwan \\ * Correspondence: binhao17@gmail.com; Tel.: +886-2-2-2771-2171 (ext. 3604)
}

Citation: Hung, C.-J.; Chen, W.-J.; Lin, C.-A.; Shiu, H.-R.; Chen, B.-H. Effect of Metallic Bipolar Plates Fillet Radii on Fuel Cell Performance. Energies 2021, 14, 7109. https:// doi.org/10.3390/en14217109

Academic Editor: Attilio Converti

Received: 26 September 2021

Accepted: 20 October 2021

Published: 1 November 2021

Publisher's Note: MDPI stays neutral with regard to jurisdictional claims in published maps and institutional affiliations.

Copyright: (c) 2021 by the authors. Licensee MDPI, Basel, Switzerland. This article is an open access article distributed under the terms and conditions of the Creative Commons Attribution (CC BY) license (https:/ / creativecommons.org/licenses/by/ $4.0 /)$.

\begin{abstract}
This paper studies the effects of compression, deformation, and the contact area in the membrane electrode assembly (MEA). The electrical impedance of fuel cell stacks due to the assembly of the metallic bipolar plates is also considered. According to decades-long fuel cell (FC) assembly experience, an increase in compression force can result in adequate contact resistance, but excessive compression may cause extra contact resistance and damage to the MEA structure. The study suggests a design for improving the performance of the FC stack by proposing different fillet radii metallic bipolar plates. It is found that the appropriate fillet radius reduces contact resistance by $13 \%$ and avoids the accumulation of compression, thereby maintaining contact resistance at adequate levels. The current design proposes a simple and effective method to minimize the dimension tolerance of single fuel cell units and support sufficient compression.
\end{abstract}

Keywords: contact resistance; metallic bipolar plate; fuel cell

\section{Introduction}

In 2015, in a bid to accelerate the commercialization, popularization, and steady use of fuel cell technology, the Toyota Motor Corporation announced the free licensing of 5680 fuel cell patents [1]. Fuel cells have potential applications due to their potential for clean power generation, in addition to their smaller sizes, high energy efficiency, and long product life (10-15 years) [1]. As a result, in addition to automakers, other business entities, such as mobile device producers (smartphone and laptops), have been scrambling to enter this market. In addition to the hydrogen fuel source, the assembly of fuel cell stacks constitutes another essential feature. Both the flow channel design and bipolar plate stacking procedure are critical factors in terms of the generation capacity and life cycle of fuel cells. The art of single cell stacking calls for various applications involving corresponding mechanisms to ensure sufficient compression force and, thus, effective contact, which reduces contact resistance. In general, a fuel cell stack comprises two end plates and corresponding bolts, which are then secured with a torque wrench to form an FC. The design requires the use of compressive force on both end plates, and limitations to be applied on the number of regions to be secured within the stacking cell. To support the non-equilibrium stress field of bonding around bolts and end plates, as well as differential pressure in the MEA, the end plates are often thickened; however, this causes increases in weight and cost [2-6]. Therefore, to avoid the need for higher compression force via complex cell-stack design, the control of contact resistance is a crucial factor in the stacking of fuel cells. In order to minimize the tolerance in single cells, as well as to optimize the parameters and reduce the influence of uncertain factors between the MEA and metallic bipolar plates, we suggest a novel stacking procedure design. Metal bipolar plates have 
potential use as a material for bipolar plates due to several advantages that they offer. Due to the characteristic of metal plasticity, they can be formed into desired shapes. During the operation of PEMFC, metallic materials are susceptible to corrosion in acidic and humid operating environments. Metals decompose when the fuel cells are operating within a corrosion environment.

The paper is divided into five main parts. The second section of the paper describes the basic features of three proposed metal bipolar plate designs and briefly explains the assembly process of a bipolar plate module. Section 3.1 outlines the relationship between the characteristic angle, compression ratio, and MEA thickness, while Section 3.2 explores the relationship between the characteristic angle, compression rate, and resistance value. Finally, in the Discussion section, the question as to whether the characteristic angle design can produce the expected effect is examined.

\section{Materials and Methods}

After undertaking a mechanical cold working process without appropriate thermal treatment, metal pieces may exhibit residual stress, which may lead to stress corrosion cracking (SCC) over a certain period. Moreover, high temperature and various oscillation factors [7-9] of the flow channel may shorten the life of the metallic bipolar plate assembly. Corrosion resistance is higher in hot environments that are permeated with dissolved oxygen. The higher the electrical conductivity, sensitization time, sensitization temperature, and material carbon content, the more likely the occurrence of inter-granular SCC [10-13]. Electroplating, PVD, and polymer coating on the surface of metallic bipolar plates can reduce resistivity and increase corrosion resistance [14-17]. The most common forms of metallic flow channels are pin-type, parallel, serpentine-integrated, and interdigitated channels $[18,19]$. Some studies have found that water appears in cathode-side flow channel due to electrochemical reactions. Electroosmotic force caused by high current density increases the volume of water formed at the electrode, which outpaces the volume of water removed, leading to water clogging and the hampering of fuel cell performance. When fuel gas in an interdigitated flow channel passes the forced convective flow, the air flow induces shear stress, thereby reducing the relatively large volume of liquid water and alleviating the water clogging problem [20]. Previous studies [21,22] have analyzed the influence of oxygen consumption caused by the gas flow channel on the cathode side of proton-exchangemembrane fuel cells (PEMFC), finding that the order of the reaction and the length of the flow channels affects fuel cell performance. When the order of reaction increases, the inlet electric current increases, decreasing the overall fuel cell performance while the limiting current density remains unchanged. When the flow channel length increases, the amount of fuel in the flow channel may become insufficient, thereby decreasing the effective operation area. Therefore, in addition to the flow channel's inlet parameters, its shape and length may affect the fuel efficiency. Stainless steel has several disadvantages when applied in cutting, including the formation of a hardened layer on the surface when subjected to a tooling process. The hardened surface can cause considerable friction between the cutting tool and the material, sharply raising the temperature and reducing the cutting force. Given its characteristics, stainless steel does not chip easily and tends to adhere to the contact face of the cutting edge, thereby damaging the cutting tool $[23,24]$. Hydroforming pressure affects the work piece during the formation process [25]. A study showed that appropriate control of hydraulic pressure can not only assist in material feeding but also ward off defects, such as wrinkles and cracks. Under different hydraulic pressures [26,27], the relationship between residual stress and process parameters affects products' surfaces and dimensional accuracy levels. This study employed stamped and formed products that were not fully annealed, along with anisotropic materials. The directionality was analyzed to determine the plastic strain ratio, denoted as $r$, as well as the ratio of the lateral strain to the thickness strain of the specimen during tensile testing (Equation (1)). The physical interpretation of $\mathrm{r}$ is related to impedance caused by the thinning of materials, 
with a greater $r$ value indicating greater difficulty in the deformation of thickness during the formation process [28].

$$
\mathrm{r}=\frac{\varepsilon_{w}}{\varepsilon_{t}}
$$

where $\varepsilon_{w}$ is the lateral strain and $\varepsilon_{t}$ is the thickness strain

Assuming that the volume remains unchanged,

$$
\mathrm{S}=\frac{-d \varepsilon_{w}}{d \varepsilon_{1}}=\frac{-d \varepsilon_{w}}{-\left(d \varepsilon_{t}+d \varepsilon_{w}\right)}=\frac{\mathrm{r}}{1+\mathrm{r}}
$$

where $d \varepsilon_{1}$ stands for the axial strain increment. $\varepsilon_{w}$ and $\varepsilon_{1}$ are used as vertical and horizontal axes, respectively. Linear regression analysis was conducted to determine the slope, which was then converted in Equation (3) to determine r.

$$
\mathrm{r}=\frac{\mathrm{S}}{1-\mathrm{S}}
$$

\subsection{Contact Resistance Theory}

Fuel cell performance is mainly affected by the contact resistance between the gas diffusion layer (GDL) and the metallic bipolar plates, as well as the porosity of GDL, both of which are, in turn, influenced by contact pressure between the metallic bipolar plates and the GDL. Therefore, theoretically, the relationship between contact pressure and fuel cell performance can be quantified [29-35] as follows:

$$
V_{\text {cell }}=V_{\text {ideal }}-\Delta V_{\text {act }}-\Delta V_{\text {ohm }}-\Delta V_{\text {conc }}-\Delta V_{\text {internal }}
$$

where $V_{\text {cell }}$ is the cell voltage, $V_{\text {ideal }}$ the ideal voltage, $\Delta V_{\text {act }}$ the activation overpotential, $\Delta V_{\text {ohm }}$ the ohmic overpotential, and $\Delta V_{\text {conc }}$ the concentration overpotential. The variable $\Delta V_{\text {internal }}$ denotes the voltage loss due to the effect of assembly. The voltage loss caused by these variables has been discussed in various studies and can be calculated theoretically and experimentally.

The contact pressure between the GDL and the bipolar plates affects the contact resistance. The conductivity of the material also determines its resistance. Thus, the total resistance of the fuel cell can be expressed as follows:

$$
\begin{gathered}
R=R_{B}+R_{\frac{G}{B}}+R_{G} \\
R_{\frac{G}{B}}=R\left(\frac{1}{p}\right)^{c}
\end{gathered}
$$

where $R_{B}$ and $R_{G}$ are the resistance values of the bipolar plate and the directly measurable GDL, respectively; $R_{G / B}$ is the contact resistance between the bipolar plate and the GDL, obtained through Equation (2).

In addition to voltage, current and resistance must be taken into account in the calculation of fuel cell performance. Total resistance in the cell assembly is the sum of the resistances of components and contact resistance. The contact pressure and the resistance equation were secured experimentally. Contact resistance was calculated based on the concept of parallel connection [7], according to which contact resistance hinges on contact pressure. However, excessive contact pressure may damage the GDL, impeding fuel cell performance. Therefore, four designs were formulated, with different radiuses $(R ; 0,0.3$, 0.5 , and $0.7 \mathrm{~mm}$ ), to achieve different flow channel features, as shown in Figure $1 \mathrm{a}, \mathrm{b}$. The radial difference enables metallic plates to generate suitable bending and deformation to disperse contact pressure, reducing the pressure on the GDL. Following the assembly of the flow channels, the relationships between the compression ratios and the contact resistance were measured, as a reference for optimizing fuel cell assembly. 


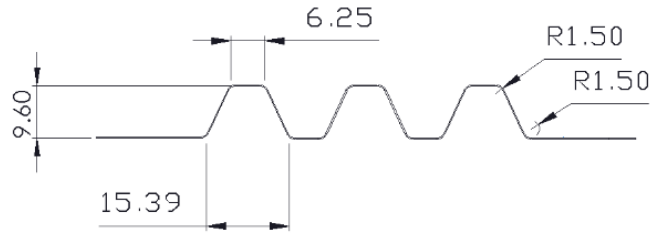

(a)

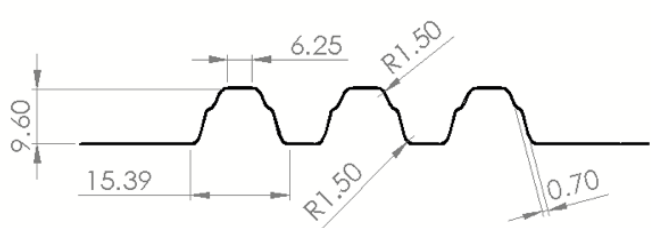

(b)

Figure 1. Flow channel features with fillet radii of (a) 0 and (b) $0.70 \mathrm{~mm}$.

\subsection{Assembly Procedure}

First, a metallic bipolar plate, made of 0.15-mm-thick SUS 316L metal sheet [36], was fabricated via multiple progressing stamping functions to produce a straight cathode channel. Metallic bipolar half-plates with different fillet radii were also made via a constant stamping process with stamping dies at different angles. In the final stamping step, the deformed channel-shaped metallic sheets needed to be pressed again to ensure accurate channel height.

A thermosetting airtight component, $0.59 \mathrm{~mm}$ thick, was created and combined with cathode-anode metallic bi-polar plate to form a modularized unit; the structure is shown in Figure 2. Another key component was the MEA module, shown in Figure 3b. Metal frame gaskets for anode flow channel plates, as shown in Figure 3a, were fabricated with SUS 316L stainless steel via stamping. Thermoplastic films were placed in jigs before the placement of the stainless frame gasket for clamping, followed by the placement and fixation of the anode metal frame (film side up), MEA (cathode side up), and cathode metal frame (film side down), in this order. Then, the assembly module was placed in a thermoforming machine for thermoforming, as shown in Figure 2.

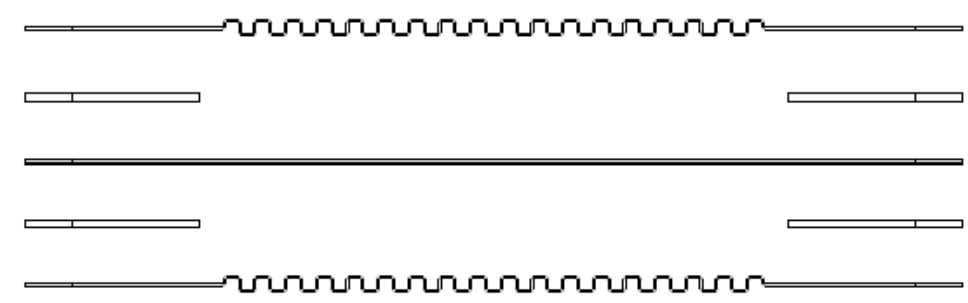

Figure 2. Bipolar plate module illustration in the study.

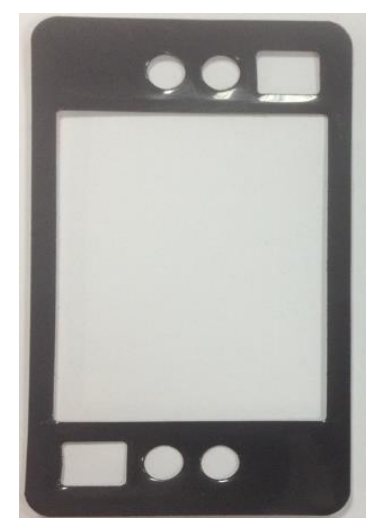

(a)

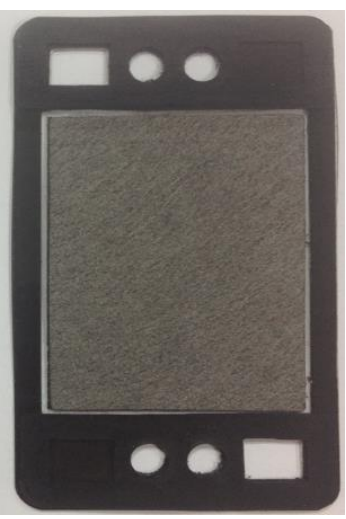

(b)

Figure 3. (a) Frame gaskets; (b) gas diffusion layer and thermoplastic film.

The gasket/separator was employed in the bipolar module, as shown in Figure 2, and the metal border was adhered with thin film, forming a 7-layer MEA module with robust structure. The two modules formed a stable mechanical stacking. The gasket/separator, 
shown in Figures 2 and 3, respectively, had two major functions. The first function was gas sealing: the gasket and adhesive film were bound via hot pressing between the anode and cathode of the metallic flow plate, forming a modularized unit, known as a "bipolar plate module." Gaskets [37] that are made of anti-corrosion plastic function as manifolds for anode gas, hydrogen, and cathode air, avoiding gas crossover, as shown in Figure 2. The second function was the MEA border: with a metal border adhered with thin film in the modularization of the MEA, a robust stack was assembled. A pair of thin rubber gaskets between the two sides of MEA module sealed the gas. Therefore, with compression force applied in the GDL of the 7-layer MEA, the gasket/separator allowed a small amount of compression, enabling gas sealing. The compression ratio was defined for the flat-press deformation of MEA (or GDL).

\subsection{Stack Assembly}

The anode side of the aforementioned metallic bipolar plate modules was bound with airtight anode gaskets prior to contact with the anode side of the MEA module, and was then placed on the anode side of the flow channel. Then, airtight cathode gasket was placed in the airtight areas of the left and right sides. The process was repeated six times before the formation of a six-cell stack assembly. There were four MEA compression ratio design values: $30 \%, 40 \%, 43 \%$, and $46 \%$. The measurement standard was the sum of the measurement values of the MEA module and the anode side of the flow channel. Subsequently, a leakage test of the stack assembly was conducted. A nitrogen source was connected to end-plate sockets under the pressure of $0.64 \pm 0.03$ bar. Afterwards, the nitrogen sources were turned off for two minutes to confirm the leakage by means of pressure observation. The maximum allowable leakage was set at $5 \%$ ( $0.032 \mathrm{bar})$. The assembly of the fuel cell stack is shown in Figure 4.

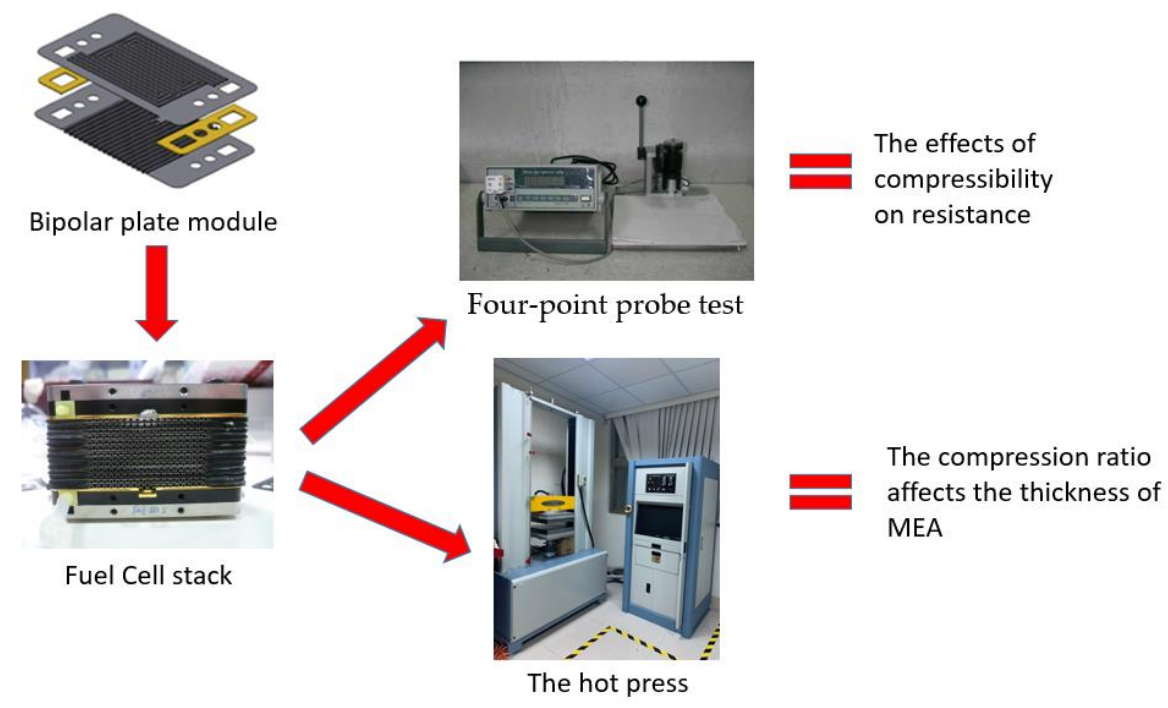

Figure 4. Experimental schematic flow.

\subsection{Experiment Method}

In this step, we prepared the bipolar plate modules for assembly of the FC stack. We measured the resistance of the bipolar plate modules with the four-point probe method and then used a hot press to set different compression ratios for the measurement of the thickness. The measuring equipment and assembling steps are shown in Figure 4.

\section{Results}

3.1. Effect of Fillet Radii and Compression Ratio

As shown in Figure 5, the thickness of the MEA decreased gradually as the compression ratio increased. In addition, it was found that an excessive compression ratio 
would reduce the porosity of the GDL and affect the gas diffusion capacity of the fuel cell assembly, thereby lowering the current-density limitation. However, previous studies have shown that excessively low pressure may cause higher contact resistance [1-6,29]. In addition, appropriate pressure can achieve the required air density and surface resistance, thereby improving thickness, while arbitrary increases in pressure will have the opposite effect. Therefore, in this study, four different curvatures " $R$ " ( $R=0,0.3,0.5,0.7 \mathrm{~mm})$ were designed, which were associated with four compression ratios (30\%, 40\%, 43\% and $46 \%$ ), respectively, so as to avoid uneven distributions of pressure, which can cause deformation during the assembly process.

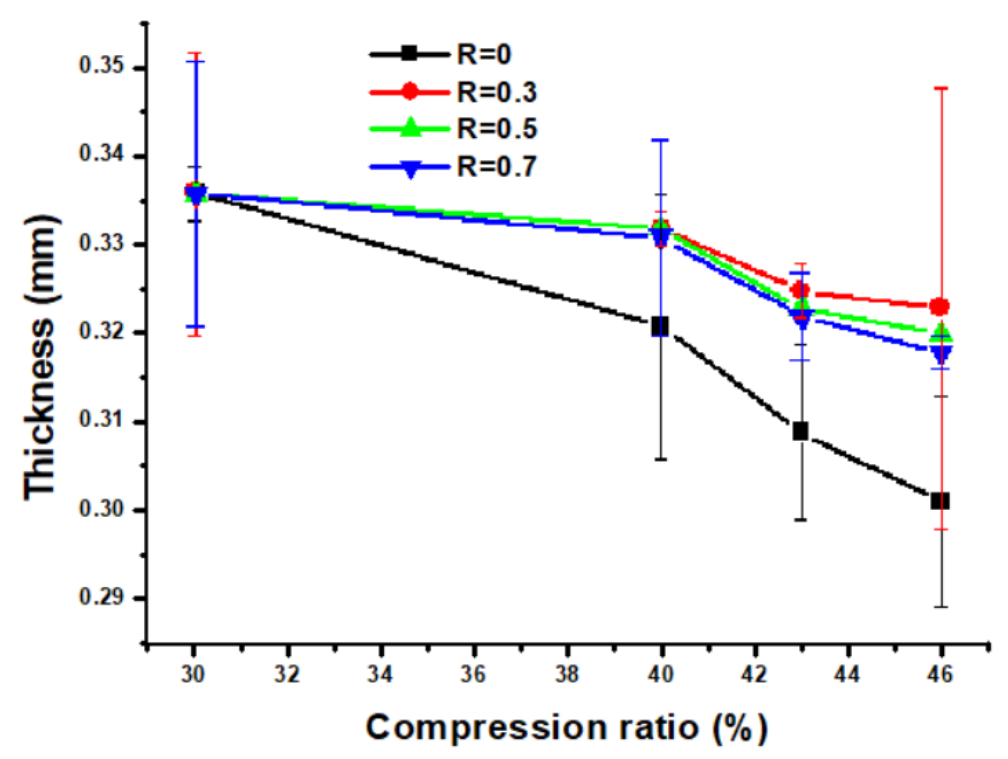

Figure 5. Influence of compression ratio and fillet radius on the thickness of MEA.

As shown in Figure 5, with the compression ratio at 30\%, there was no significant difference in the average MEA thickness as compared to the $40 \%$ compression ratio, for which the thickness difference was $104.6 \%$ at $R=0 \mathrm{~mm}, 104.3 \%$ at $\mathrm{R}=0.3 \mathrm{~mm}, 104.3 \%$ at $\mathrm{R}=0.5 \mathrm{~mm}$, and $101.5 \%$ at $\mathrm{R}=0.7 \mathrm{~mm}$. With the compression ratio at $43 \%$, the thickness difference was $108.7 \%$ at $\mathrm{R}=0 \mathrm{~mm}, 103.3 \%$ at $\mathrm{R}=0.3 \mathrm{~mm}, 104 \%$ at $\mathrm{R}=0.5 \mathrm{~mm}$, and $104.3 \%$ at $\mathrm{R}=0.7 \mathrm{~mm}$, as compared with the $46 \%$ compression ratio, for which the thickness difference was $111.6 \%$ at $R=0 \mathrm{~mm}, 104 \%$ at $\mathrm{R}=03 \mathrm{~mm}, 105 \%$ at $\mathrm{R}=0.5 \mathrm{~mm}$, and $105.6 \%$ at $\mathrm{R}=0.7 \mathrm{~mm}$. With the value of $\mathrm{R}$ set at $0 \mathrm{~mm}$, the compression ratio remained unchanged; the other three values $(R=0.3,0.5,0.7 \mathrm{~mm})$ had the largest difference in MEA thickness $(111.6 \%)$, while the thickness difference was the smallest $(104 \%)$ at $\mathrm{R}=0.3 \mathrm{~mm}$.

Regarding the compression ratio of MEA featuring a channel shape without a fillet radius (i.e., $\mathrm{R}=0 \mathrm{~mm}$ ), the total thickness was found to mostly be caused by non-proportional deformation triggered by the GDL with a carbon fiber structure. The channel surface with a metal fillet radius was forced to bend locally at $R=0 \mathrm{~mm}$, because of which the carbon fiber deformed through bucking and exhibited lower total thickness under higher compression ratios (Figure 5). Figure 6 shows the imprints of the anode serpentine channel and the straight cathode channel on the GDL surface. The upper left corner of the figure exhibits deformation marks caused by excessive pressure and the lower right corner displays the usual marks.

Figure 5 shows that the MEA thickness had its minimum value at $\mathrm{R}=0 \mathrm{~mm}$, with a $46 \%$ compression ratio. Non-linear deformation appeared on the top. The fillet radius effect of $\mathrm{R}=0.3,0.5$, and $0.7 \mathrm{~mm}$ may have contributed to the uniform deformation of the MEA within the quasi-elasticity of metal channel structure. In addition, as the amount of compression increased, the metal surface had partial contact with the GDL, followed by the surface fibers that were perpendicular to the contact surface either breaking or spreading 
and deforming, without significant changes in thickness when the compression ratio exceeded $40 \%$. At $\mathrm{R}=0.7 \mathrm{~mm}$, with compression exceeding $46 \%$, resistance reappeared.

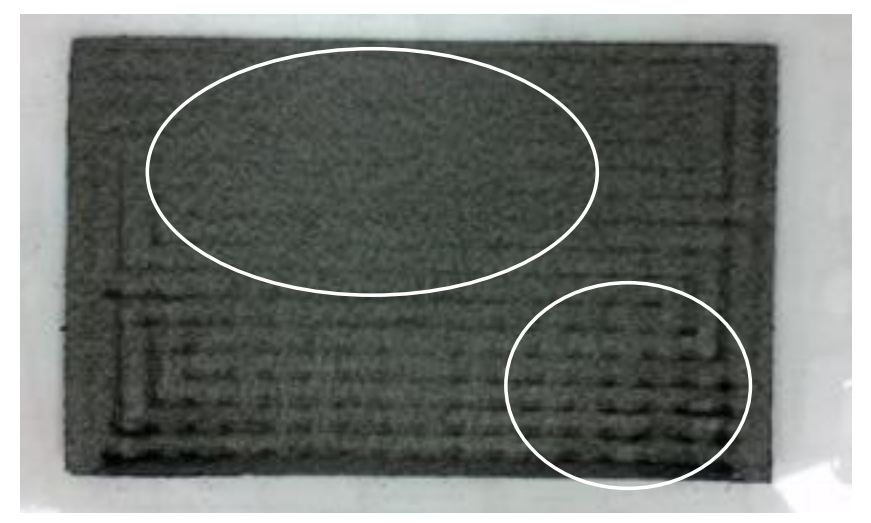

Figure 6. Surface indentation of GDL at $\mathrm{R}=0$.

\subsection{Effect of Fillet Radii and Compression Ratios on Resistance}

Figure 7 displays the relationship between the compression ratios (in this section, the study analyzes the contact resistance at compression ratios of 30\%, $40 \%, 43 \%$, and $46 \%$ ). Therefore, to obtain a significant value, compression force was employed with different sized radii, with variations in the ratios of the percentage values of contact resistance. The ratio percentage can be shown as a non-unit value to indicate a smaller value with difference $\mathrm{R}$-versus-compression ratios and resistance for difference fillet radii $(0,0.3,0.5$, and $0.7 \mathrm{~mm}$ ), with an overall compression ratio of $53 \%$. The resistance with a characteristic angle of $0 \mathrm{~mm}$ at $30 \%$ compression stood at $5.98 \mathrm{~m} \Omega$, as compared with $4.62 \mathrm{~m} \Omega$ for $46 \%$ compression. The resistance was reduced by $29.4 \%$. The resistance with a characteristic angle of $0.5 \mathrm{~mm}$ at a $30 \%$ compression ratio dropped to $4.88 \mathrm{~m} \Omega$, as compared with $2.88 \mathrm{~m} \Omega$ for the $46 \%$ compression rate, with a $69 \%$ reduction in resistance. The resistance with a characteristic angle of $0.7 \mathrm{~mm}$ at $30 \%$ compression dropped to $4.62 \mathrm{~m} \Omega$, as compared with $2.13 \mathrm{~m} \Omega$ for $46 \%$ compression. With the overall compression ratio remaining at $53.3 \%$, resistance was reduced by $116.9 \%$. In general, with a $30 \%$ compression ratio, the resistance difference between characteristic angles $0 \mathrm{~mm}$ and $0.7 \mathrm{~mm}$ reached $29 \%$; with a $46 \%$ compression ratio, the difference in resistance between the distinct angles of $0 \mathrm{~mm}$ and $0.7 \mathrm{~mm}$ came to $104.69 \%$.

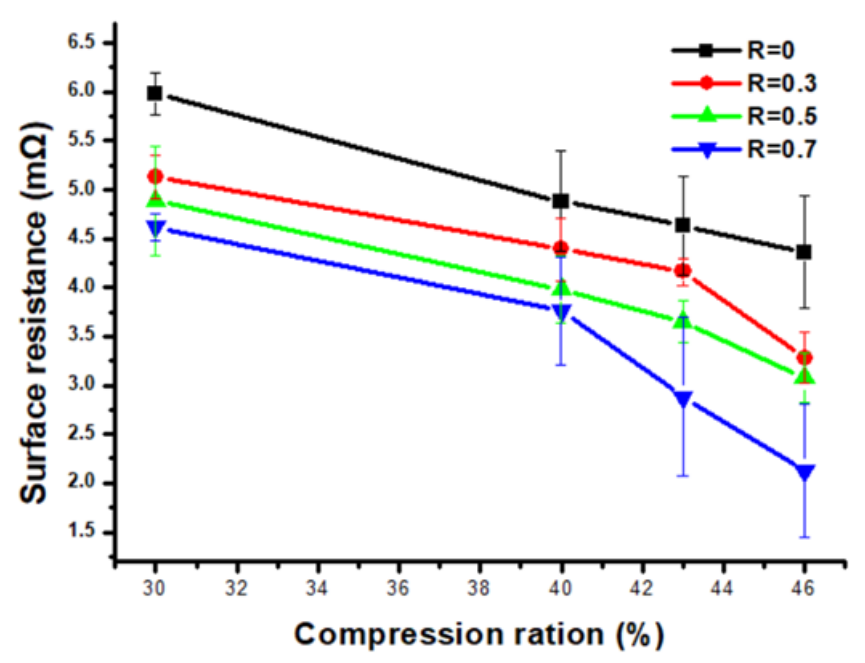

Figure 7. Effects of fillet radius and compressibility on resistance.

A characteristic angle was added to the optimal design, thereby increasing the average contact surface between the runner and the MEA and, as a result, reducing the contact 
resistance. Without a characteristic angle, the contact resistance continued to drop. Then, the compression ratio was increased. In this case, the MEA may have incurred excessive pressure, which would have resulted in regional damage, risking a substantial drop in the efficiency of the fuel cell stack. Therefore, in this study, different characteristic angles were selected to compare their differences. Figure 8a includes a comparison between various characteristic angles for $0 \mathrm{~mm}$ with a $30 \%$ compression rate, while Figure $9 \mathrm{~b}$ shows a similar comparison for $0 \mathrm{~mm}$ with a $46 \%$ compression rate. There were apparent voids on the contact surface of the metal bi-level plate. At higher compression ratios, gaps were significantly reduced (Figure 5) and the contact resistance was lower. Figure 9a shows that at the $0.7 \mathrm{~mm}$ characteristic angle with a $30 \%$ compression rate, the contact surface of the metal double-stage plate was relatively flat with no noticeable gap, as compared with that in Figure 8a. The contact surface was even flatter at a characteristic angle of $0.7 \mathrm{~mm}$ with a $46 \%$ compression rate, as shown in Figure $9 \mathrm{~b}$. Figure 7 displays the phenomenon of resistance. With the same compression ratio, a better contact resistance could be derived from an appropriate characteristic angle. It was found that, in general, MEA pressure can be reduced with a right angle, thereby increasing the reliability of fuel cell stack based on the presence of a lower clamping force.

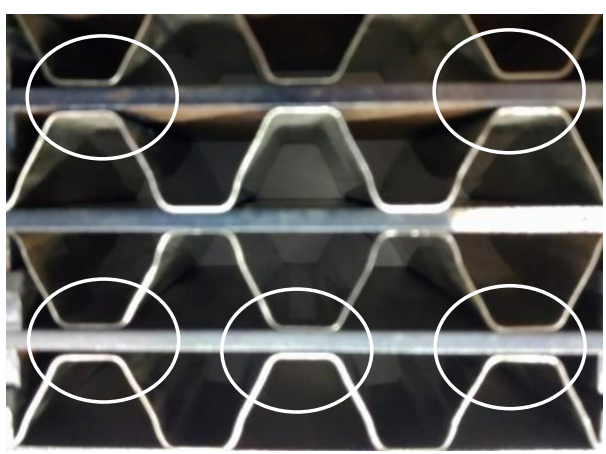

(a)

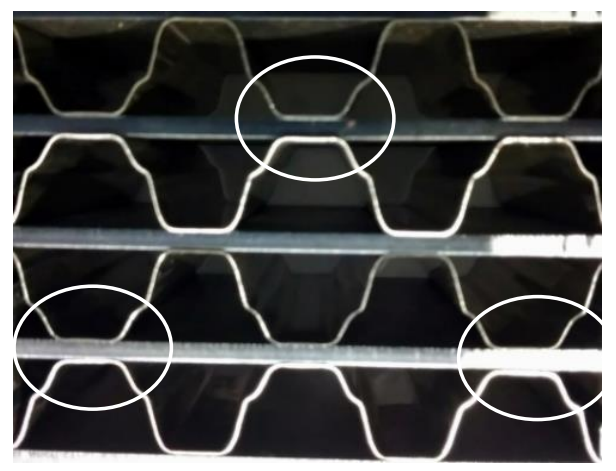

(b)

Figure 8. Significant fillet radii of $0.7 \mathrm{~mm}$ with compression ratios of (a) $30 \%$ and (b) $46 \%$.

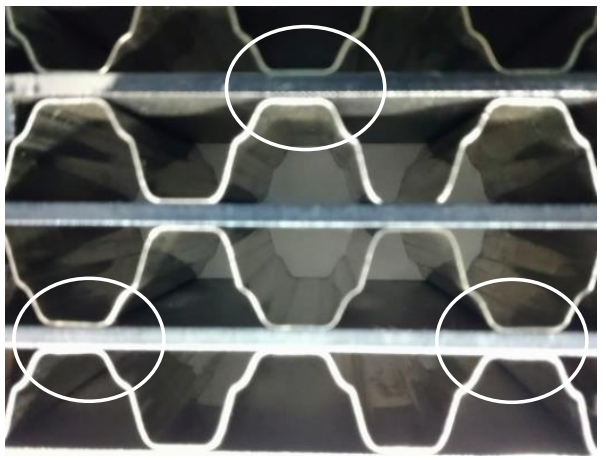

(a)

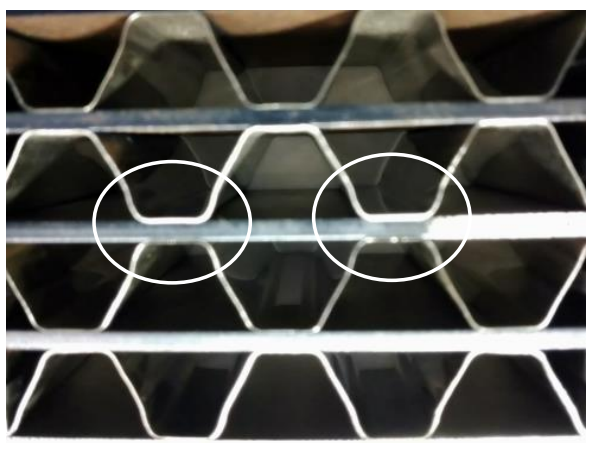

(b)

Figure 9. Characteristic angle with compression ratios of (a) $30 \%$ and (b) $46 \%$.

\section{Discussion}

The research aimed to obtain the optimal contact resistance value with minimal changes in the flow channel design, thereby improving fuel cell performance. To determine whether the mechanical activation of the metallic bipolar plate is suitable in terms of ensuring the sufficient performance of PEMFC, the effects of the contact resistance induced by stacking compression were examined. For four different cross section morphologies of the flow channel, with compression ratios of $30 \%, 40 \%, 43 \%$, and $46 \%$, which are associated with different fillet radii, experimental data concerning contact resistance are available. 
Under the condition of a $46 \%$ compression rate and an angle of $0.7 \mathrm{~mm}$, the lowest surface resistance $(2.13 \mathrm{~m} \Omega)$ was observed, while the highest surface resistance occurred at $(30 \%$, $0.0 \mathrm{~mm}$ ). The original concept for the design of bipolar plates was centered around the fillet radii. These new structures strengthen the out-plane stiffness of the metallic plate, enhance their elasticity, and prevent the deformation of plasticity. The results show that higher plate elasticity can transmit the clamping pressure to a contact pressure due to the fillet radii design. It is clear that higher contact pressure will reduce the contact resistance. This study examined the effect of fillet radii and compression ratios on MEA thickness, finding that the optimal MEA thickness could be obtained at $\mathrm{R}=0.3 \mathrm{~mm}$ with $40 \%$ compression ratio, followed by $\mathrm{R}=0.7 \mathrm{~mm}$ with $43 \%$ compression ratio. It was also discovered that resistance was relatively low at $R=0.7 \mathrm{~mm}$. By analyzing the effect of the interactions of the contact pressure of the fuel cell stack on the thickness and resistance of the MOA, the study concluded that it is better to design a fillet radius with $\mathrm{R}=0.7 \mathrm{~mm}$ in the flow channel. According to the literature review and the experimental results, pressure between the metallic bipolar plates and the MEA in the cell stack assembly significantly influences the contact resistance. This study put forth methods to ensure effective contact between the metallic bipolar plates and the MEA while avoiding any local or global deformities that can be caused by excessive pressure. Excessive pressure might induce excessive porosity, hampering gas diffusion in the fuel cell stack and reducing the current density, but insufficient pressure could cause excessively high contact resistance. Therefore, the fuel cell stack needs optimal clamping pressure to attain optimal performance.

The study demonstrated that the addition of appropriate fillet radii can alleviate the uneven distribution of compression ratios and that the designs including $0.7 \mathrm{~mm}$ fillet radii can reduce the contact resistance even at low compression ratios.

\section{Conclusions}

In recent years, electrical vehicles, including pure and hybrid models, have become increasingly popular, outperforming other renewable-energy vehicles by a large margin, such as those powered by PEM fuel cells, whose development has been constrained by the high cost of fuel cell stacks and hydrogen generation. The development of metallic stacks for PEM fuel cells been faced with the issues of performance and cost, which constitute major barriers to their commercialization. The development of metallic bipolar plates with high-power density stacks is critical. In addition, metallic bipolar plates should be able to significantly raise resistance, including contact resistance and electromechanical resistance. The study unveils a novel cathode channel design for metallic bipolar plates, to be manufactured with high precision stamping technology. As for the fillet radius of the cathode channel, which is a key factor, two aspects, namely the MEA thickness difference and the contact resistance at the four fillet radii, were examined. This original approach offers an alternative perspective for explaining the increased resistance in PEM fuel cells with excessive clamping force in their stacks. Moreover, the fillet radii structure enhances elasticity and transforms the clamping pressure into a contact pressure. It is clear that higher contact pressure will reduce the contact resistance.

The current study also showed that when compression occurs, the MEA are deformed in a manner involving non-uniform propagation in a direction of about $45^{\circ}$ with respect to the stacking axis, while a similar zigzag mark to that of the flow channel was observed on the lower right corner. During the testing procedure, we also found that the micro-porous structure of MEA reduced the contact resistance, while its effect on the promotion of cell performance appeared to be relatively limited. The performance of PEMFC increased gradually with the increase in clamping pressure. On the contrary, the carbon loading of the MEA played important roles in terms of affecting the FC performance, while these effects may gradually reduce with higher clamping pressures.

Future studies are recommended to explore the relationship between the contact pressure of the fuel cell stack assembly and the overall voltage, current, and resistance. In addition, the optimal clamping pressure and parameters of fuel cell stack assembly 
should be calculated to maximize cell performance. The characteristic mode of metallic bipolar plates should be altered to determine the requirements for the optimization of contact resistance to ensure stable cell stack assembly and structure with the application of minimal force.

This research is a continuation of NAC 2019. For further information, please refer to https: / / www.mecc-nano.com/news/joining-the-international-conference-on-nanomaterials-andadvanced-composites-in-taiwan/ (accessed on 22 October 2021).

Author Contributions: Conceptualization, C.-J.H. and C.-A.L.; methodology, C.-J.H.; validation, C.-J.H. and W.-J.C.; formal analysis, W.-J.C. and H.-R.S.; resources, C.-J.H.; data curation, W.-J.C.; writing—original draft preparation, B.-H.C. and C.-J.H.; writing—review and editing, B.-H.C., W.-J.C. and H.-R.S. All authors have read and agreed to the published version of the manuscript.

Funding: This research received no external funding.

Institutional Review Board Statement: The study was conducted according to the guidelines of the Declaration of Helsinki, and approved by the Institutional Review Board.

Data Availability Statement: Not applicable.

Conflicts of Interest: The authors declare no conflict of interests.

\section{References}

1. Mike, R. Toyota Offers Fuel-Cell Patents to Other Car Makers: Japan's Largest Auto Maker Hopes to Spur Wider Use of Hydrogen to Power Vehicles. WSJ 2015. Available online: https:/ / www.wsj.com/articles/toyota-offers-its-fuel-cell-patents-to-other-carmakers-1420494500 (accessed on 22 October 2021).

2. Tawfik, H.; Hung, Y.; Mahajan, D. Metal bipolar plates for PEM fuel cell-A review. J. Power Sources 2007, 163, 755-767. [CrossRef]

3. Peng, L.; Lai, X. Effect of dimensional error of metallic bipolar plate on the GDL pressure distribution in the PEM fuel cell. Int. J. Hydrogen Energy 2009, 34, 990-997.

4. Vlahinos, A.; Kelly, K.; D'Aleo, J. Effect of material and manufacturing variations on membrane electrode assembly pressure distribution. In Proceedings of the International Conference on Fuel Cell Science, Engineering and Technology, Rochester, NY, USA, 21-23 April 2003; pp. 111-120.

5. Kusoglu, A.; Karlsson, A.M.; Santare, M.H.; Cleghorn, S.; Johnson, W.B. Mechanical response of fuel cell membranes subjected to a hygro-thermal cycle. J. Power Sources 2006, 161, 987-996. [CrossRef]

6. Vlahinos, A.; Kelly, K.; Mease, K.; Stathopoulos, J. Shape Optimization of Fuel Cell Molded-On Gaskets for Robust Sealing. In Proceedings of the International Conference on Fuel Cell Science, Engineering and Technology, Irvine, CA, USA, 19-21 June 2006; pp. 871-877.

7. Kim, K.S.; Lee, H.J.; Lee, B.S.; Jung, I.C.; Park, K.S. Residual stress analysis of an Overlay weld and a repair weld on the dissimilar Butt weld. Nucl. Eng. Des. 2009, 239, 2771-2777. [CrossRef]

8. Yu, X.; Chen, S.; Liu, Y.; Ren, F. A study of intergranular corrosion of austenitic stainless steel by electrochemical potentiodynamic reactivation, electron back-scattering diffraction and cellular automaton. Corros. Sci. 2010, 52, 1939-1947. [CrossRef]

9. Andresen, P.L. Factors governing the prediction of LWR component SCC behavior from laboratory data. In Proceedings of the CORROSION 99, San Antonio, TX, USA, 25-30 April 1999.

10. Saito, N.; Tsuchiya, Y.; Kano, F.; Tanaka, N. Variation of slow strain rate test fracture mode of type 304L stainless steel in $288 \mathrm{C}$ water. Corrosion 2000, 56, 57-69. [CrossRef]

11. Akashi, M.; Kawamoto, T. Stress corrosion cracking (SCC) susceptibility of various stainless steels in oxygenated high temperature water. Ishikawajima-Harima Giho 1977, 17, 472-478.

12. Umemura, F.; Akashi, M.; Kawamoto, T. Evaluation of IGSCC susceptibility of austenitic stainless steels using electrochemical reactivation method. Corros. Eng. 1980, 29, 163-169. [CrossRef]

13. Andresen, P.L. Environmentally assisted growth rate response of nonsensitized AISI 316 grade stainless steels in high temperature water. Corrosion 1988, 44, 450-460. [CrossRef]

14. Cho, K.H.; Lee, W.G.; Lee, S.B.; Jang, H. Corrosion resistance of chromized 316L stainless steel for PEMFC bipolar plates. J. Power Sources 2008, 178, 671-676. [CrossRef]

15. Yoon, W.; Huang, X.; Fazzino, P.; Reifsnider, K.L.; Akkaoui, M.A. Evaluation of coated metallic bipolar plates for polymer electrolyte membrane fuel cells. J. Power Sources 2008, 179, 265-273. [CrossRef]

16. Fu, Y.; Hou, M.; Xu, H.; Hou, Z.; Ming, P.; Shao, Z.; Yi, B. Ag-polytetrafluoroethylene composite coating on stainless steel as bipolar plate of proton exchange membrane fuel cell. J. Power Sources 2008, 182, 580-584. [CrossRef]

17. Chung, C.Y.; Chen, S.K.; Chiu, P.J.; Chang, M.H.; Hung, T.T.; Ko, T.H. Carbon film-coated 304 stainless steel as PEMFC bipolar plate. J. Power Sources 2008, 176, 276-281. [CrossRef]

18. Li, X.; Sabir, I. Review of bipolar plates in PEM fuel cells: Flow-field designs. Int. J. Hydrogen Energy 2005, 30, 359-371. [CrossRef] 
19. Song, Y.; Zhang, C.; Ling, C.Y.; Han, M.; Yong, R.Y.; Sun, D.; Chen, J. Review on current research of materials, fabrication and application for bipolar plate in proton exchange membrane fuel cell. Int. J. Hydrogen Energy 2020, 45, 29832-29847. [CrossRef]

20. Nguyen, T.V. A gas distributor design for proton-exchange-membrane fuel cells. J. Electrochem. Soc. 1996, 143, L103. [CrossRef]

21. Dohle, H.; Kornyshev, A.A.; Kulikovsky, A.A.; Mergel, J.; Stolten, D. The current voltage plot of PEM fuel cell with long feed channels. Electrochem. Commun. 2001, 3, 73-80. [CrossRef]

22. Yoon, Y.G.; Lee, W.Y.; Park, G.G.; Yang, T.H.; Kim, C.S. Effects of channel configurations of flow field plates on the performance of a PEMFC. Electrochim. Acta 2004, 50, 709-712. [CrossRef]

23. Fu, Y.; Hou, M.; Lin, G.; Hou, J.; Shao, Z.; Yi, B. Carbon-based films coated 316L stainless steel as bipolar plate for proton exchange membrane fuel cells. Int. J. Hydrogen Energy 2009, 34, 405-409. [CrossRef]

24. Fu, Y.; Hou, M.; Lin, G.; Hou, J.; Shao, Z.; Yi, B. Coated 316L stainless steel with CrxN film as bipolar plate for PEMFC prepared by pulsed bias arc ion plating. J. Power Sources 2008, 176, 282-286. [CrossRef]

25. Thiruvarudchelvan, S.; Tan, M.J. Fluid-pressure-assisted deep drawing. J. Mater. Process. Technol. 2007, 192, 8-12. [CrossRef]

26. Kleiner, M.; Krux, R.; Homberg, W. Analysis of residual stresses in high-pressure sheet metal forming. CIRP Ann. 2004, 53, 211-214. [CrossRef]

27. Hatch, J.E. Aluminum: Properties and physical metallurgy. In Asm International Handbook Committee, 1st ed.; Aluminum Association Inc. and ASM International: USA, 1984.

28. Tsai, J.; Sun, C.T. Constitutive model for high strain rate response of polymeric composites. Compos. Sci. Technol. 2002, 62, 1289-1297. [CrossRef]

29. Lai, X.; Ni, J.; Peng, L.; Lan, S.; Lin, Z. Robust design of assembly parameters on membrane electrode assembly pressure distribution. J. Power Sources 2007, 172, 760-767.

30. Wang, H.; Sweikart, M.A.; Turner, J.A. Stainless steel as bipolar plate material for polymer electrolyte membrane fuel cells. J. Power Sources 2003, 115, 243-251. [CrossRef]

31. Greenwood, J.A.; Williamson, J.P. Contact of nominally flat surfaces. Proc. R. Soc. London. Ser. A Math. Phys. Sci. 1966, 295, 300-319.

32. Majumdar, A.; Tien, C. Fractal network model for contact conductance. J. Heat Transf. 1991, 113, 516-525. [CrossRef]

33. Mishra, V.; Yang, F.; Pitchumani, R. Measurement and prediction of electrical contact resistance between gas diffusion layers and bipolar plate for applications to PEM fuel cells. J. Fuel Cell Sci. Technol. 2004, 1, 2-9. [CrossRef]

34. Zhou, P.; Wu, C.W.; Ma, G.J. Contact resistance prediction and structure optimization of bipolar plates. J. Power Sources 2006, 159, 1115-1122. [CrossRef]

35. Zhang, L.; Liu, Y.; Song, H.; Wang, S.; Zhou, Y.; Hu, S.J. Estimation of contact resistance in proton exchange membrane fuel cells. J. Power Sources 2006, 162, 1165-1171. [CrossRef]

36. Kong, D.; Dong, C.; Ni, X.; Zhang, L.; Luo, H.; Li, R.; Li, X. Superior resistance to hydrogen damage for selective laser melted 316L stainless steel in a proton exchange membrane fuel cell environment. Corros. Sci. 2020, 166, 108425. [CrossRef]

37. Talebi-Ghadikolaee, H.; Elyasi, M.; Mirnia, M.J. Investigation of failure during rubber pad forming of metallic bipolar plates. Thin-Walled Struct. 2020, 150, 106671. [CrossRef] 